\title{
ASSESSING THE IMPACT OF CLIMATE CHANGE ON SOIL WATER BALANCE IN THE LOESS PLATEAU OF CHINA
}

\author{
Zhi Li ${ }^{1,2, *}$, Wenzhao Liu ${ }^{2}$, Xunchang Zhang ${ }^{3}$ \\ ${ }^{1}$ College of Resources and Environmental Science, Northwest Sci-Tech University of \\ Agriculture and Forestry, Yangling Shaanxi 712100, China; \\ ${ }^{2}$ Institute of Soil and Water Conservation, Chinese Academy of Sciences and Ministry of \\ Water Resources, Yangling Shaanxi 712100, China; \\ 3 USDA-ARS Grazinglands Research Laboratory, El Reno, OK, USA. \\ * Corresponding author, Address: College of Resources and Environmental Science, \\ Northwest Sci-Tech University of Agriculture and Forestry, Yangling Shaanxi 712100, \\ China; Tel: +86-29-87011683,Email:lizhibox@126.com
}

Abstract: Soil water balance has response to climate change and evaluation of soil water change is one of the most important items of climate change impact assessment. GCM outputs under three scenarios were statistically downscaled during 2010 2039 to simulate the potential change of soil water balance in Wangdonggou watershed on the Loess Plateau with WEPP model. GCM predicted a 1.8 to $17.5 \%$ increase in annual precipitation, 0.5 to $0.9{ }^{\circ} \mathrm{C}$ rises in maximum temperature, 2.0 to $2.3{ }^{\circ} \mathrm{C}$ rise in minimum temperature for the region. Plant transpiration will mainly change from April to June and soil evaporation mainly changed during July to September. Percent increases under climate changes, as averaged for each emissions scenario and slope, ranged from -5 to $19 \%$ for crop transpiration, -4 to $4 \%$ for soil moisture, -7 to $7 \%$ for soil evaporation, 6.5 to $44.1 \%$ for wheat grain yield, 26.3 to $41.7 \%$ for maize yield. Climate change will affect soil water balance significantly and some countermeasures are necessary.

Keywords: climate change; soil water balance; GCM, WEPP, CLIGEN

Please use the following format when citing this chapter:

Li, Z., Liu, W. and Zhang, X., 2009, in IFIP International Federation for Information Processing, Volume 294, Computer and Computing Technologies in Agriculture II, Volume 2, eds. D. Li, Z. Chunjiang, (Boston: Springer), pp. 871-880. 


\section{INTRODUCTION}

As the main constituent of terrestrial ecosystem, the functions and processes of soil changes in response to global climate change. Soil water reserve is one of the main sources of water that can be utilized by vegetation. The potential change of soil water induced by climate change may cause great change to ecological environment and agricultural production. As unique geomorphic units with fragile ecological environment, the potential changes of soil water in future on the Loess Plateau need to be assessed.

The current researches about impact of climate change on soil water are carried out mainly through integration of ecological models with future climate scenarios (Huszar et al., 1999; Mehrotra, 1999; Naden and Watts, 2001; Pan et al., 2001; Ramos and Mulligan, 2005; Zhang and Liu, 2005). The climate change scenarios used in these studies falls in two groups, one is from synthesis and the other is from GCM output. The former was derived according to some laws of climate change; the latter was the most popular method of developing climate change scenarios for GCM.

When GCMs are used to assess the impacts of climate change, two major obstacles exist in the site-specific impacts assessment. These obstacles are spatial and temporal scale mismatches between coarse resolution projections of GCMs and fine resolution data requirements of agricultural systems models(Hansen and Indeje, 2004). Various methods are developed to bridge the spatiotemporal gaps, which can be divided into two kinds: dynamic and empirical (statistical) approaches. Dynamic downscaling is used to achieve higher spatial resolutions by nesting Regional Climate Models (RCM) within GCM output fields. RCM output is computationally costly and quantitatively heavy (Solman and Nunez, 1999), and is only available for limited regions. Statistical technique derives statistical relationships between observed local climatic variables (predictands) and large scale GCM output (predictors) using regression-type methods, and applies this relationship to GCM future output to get the information of future climate change. Statistical methods are easily implemented and can be calibrated to local situation, therefore, statistical methods are frequently used to downscale GCM projections to finer spatiotemporal scales. A diverse range of statistical downscaling techniques has been developed. Those techniques in principle fall in three categories: weather generators, transfer functions, and weather typing schemes (Chen, 2000; Wilby et al., 1998).

At present, the research about impacts of climate change on soil water in China is mainly theoretical discussion rather than quantitative studies. When quantification was carried out, large scale GCM outputs were usually used directly. GCM cannot take into account the difference of regional condition, therefore, using GCM grid outputs directly to assess site-specific impact of climate change is not reliable(von Storch, 1995). These studies contributed to the development of impact assessment of climate change on soil, however, 
more detailed climate scenarios needed to be developed to carry out climate change impact. Owing to the limited use of RCM, empirical approach should be discussed further.

The objectives of this study were to (i) spatially downscale GCM grid output with a new statistical approach to Wangdonggou watershed on the Loess Plateau and temporally downscale GCM monthly output to daily series data using CLIGEN; (ii) evaluate the potential impacts of HadCM3projected climate changes during 2010-2039 under A2a, and B2a, and GGa1 on soil water balance (Soil water, soil evaporation, plant transpiration and percolation). Results would provide reference information for ecological environment construction and agricultural production in the region.

\section{MATERIALS AND METHODS}

\subsection{Site description}

Wangdonggou watershed is located at Changwu County, Shaanxi Province on the Loess Plateau $\left(107^{\circ} 40^{\prime} 30^{\prime \prime} \sim 107^{\circ} 42^{\prime} 30^{\prime \prime} \mathrm{E}, 35^{\circ} 12^{\prime} 16^{\prime \prime} \sim\right.$ $\left.35^{\circ} 16^{\prime} 00^{\prime \prime} \mathrm{N}\right)$. The elevation is $946 \sim 1226 \mathrm{~m}$ above sea level. The prevailing landform is loessial tableland and gullyland, covering $35 \%$ and $65 \%$ of the watershed respectively. The loess is more than $100-\mathrm{m}$ thick on the tableland. The soil is predominantly silt loam with silt content greater than $50 \%$ (two soil series: Huangmiantu and Heilutu). The averaged annual precipitation is $582.3 \mathrm{~mm}$, with $52.8 \%$ falling in July through September. The mean annual temperature is $9.2{ }^{\circ} \mathrm{C}$. The common regional cropping system is a three-year rotation of winter wheat-winter wheat-spring maize. Rainfed agriculture is the dominant production system.

\subsection{Data sources}

Two group data are needed, viz. the CGM grid output where Wangdonggou watershed is located and the measured data of Wangdonggou watershed. Three GCM scenarios of A2a, B2a, and GGa1 from HadCM3 and three meteorologic variables (precipitation, maximum and minimum temperature) of each scenario were used. Three scenarios all include the hindcasts of 1957-2001 and the projections of 2010-2039, the measured data are from Changwu weather bureau, including daily series of precipitation, maximum and minimum temperature, wind speed and direction et al. 


\subsection{Generating climate scenarios}

\subsubsection{Spatially downscaling GCM grid outputs}

A new statistical approach proposed by Zhang (2005) was used to spatially downscale. The approach emphasizes the parity of probability distributions between measured monthly quantities and downscaled GCMprojections while it relaxes the prerequisite of strong correlationships between local measurements (predictands) and GCM output (predictors). The procedures are as following:

The GCM hindcast monthly precipitation from 1957 to 2001 was used as the control, and the historical monthly precipitation between 1957 and 2001 as the baseline. For each calendar month, the ranked observational monthly precipitation (Y-axis) was plotted with the ranked GCM-projected precipitation (i.e., paired by their ranks or corresponding quartiles of the observed vs. projected monthly precipitation, also called qq-plot). A simple univariate linear and a nonlinear function were fitted to each plot to obtain transfer functions for each month.

For impact assessment, those transfer functions were further used to downscale 2010-2039 monthly precipitation at the native GCM scale to those at the Wangdonggou watershed under the premise that the transfer functions developed under the present climate are applicable to the changed climate. For each calendar month, the nonlinear function was used to transform the projected monthly precipitation values that were within the range in which the nonlinear function was fitted, while the linear function was used for the values outside the range. The use of linear functions for the out-of-range values is to generate conservative, first order approximations. The downscaled monthly precipitation values, which represent the future monthly precipitation distribution at the Wangdonggou watershed, were then used to calculate monthly mean and variance of the changed climate for the location. Those calculated mean and variance of the downscaled monthly precipitation were used in the temporal downscaling method to generate daily weather series of the changed climate at the Wangdonggou watershed as presented in the following section.

Likewise, the GCM-projected monthly maximum and minimum temperatures were downscaled spatially in the same manner as was for monthly precipitation. Mean temperature shifts as well as variance ratios between the downscaled monthly GCM projections of 2010-2039 and the local monthly measurements of 1957-2001 were calculated for each month and were further used in temporal downscaling. 


\subsubsection{Temporally downscaling GCM monthly outputs}

Measured daily weather data of 1957-2001 at Wangdonggou watershed were used to estimate the baseline CLIGEN input parameters, which were subsequently adjusted for the relative changes to generate the changed climate scenario for the target station. The precipitation-related baseline parameters including $\mathrm{Pw} / \mathrm{w}, \mathrm{Pw} / \mathrm{d}$, mean and variance of daily precipitation of wet days were adjusted as follows. For each month, future transitional probabilities of precipitation were estimated for projected monthly means from linear relationships developed using historical transitional probability and monthly precipitation at the Changwu station. The projected monthly means were obtained by multiplying mean ratios of GCM-projected monthly precipitation between 2010-2039 and 1957-2001 by the baseline monthly precipitation means measured during 1957-2001 at the Changwu station. The mean daily precipitation per wet day, which is a CLIGEN input parameter, was analytically computed using the adjusted transitional probabilities, projected monthly mean, and number of days in the month. New variances of daily precipitation under climate change, which is another input parameter for CLIGEN, was approximated by multiplying the baseline variances derived from the daily station records by the monthly variance ratios between the target and control periods under the assumptions that transitional probabilities and autocorrelation of daily precipitation in both baseline and changed climates are similar.

Projected mean maximum and minimum temperature shifts were directly added to the corresponding baseline means. Adjusted daily temperature variances were obtained by multiplying the baseline temperature variances by the calculated variance ratios. All new parameter values were then input into CLIGEN, and 100 years of daily weather data were generated for each of three emission scenarios.

\subsection{WEPP calibration}

Measured soil, climate, crop management information, surface runoff, and sediment yield from 1988 to 1992 were used to calibrate soil erodibility parameters of the Water Erosion Prediction Project (WEPP) model (v2004.7), which was modified to incorporate the effect of elevated CO2 on plant growth and evapotranspiration. Based on the above emissions scenarios, CO2 concentration by the year 2025 would increase to $592 \mathrm{ppmv}$ (parts per million by volume) for A2a, 416 ppmv for B2a, and 445 ppmv for GGa1. Two field runoff plots and two cropping systems were selected. One runoff plot is $20.1 \mathrm{~m}$ long by $5 \mathrm{~m}$ wide with a $5^{\circ}$ slope, the other is $20.3 \mathrm{~m}$ long by, $5 \mathrm{~m}$ wide with a $10^{\circ}$ slope. A common regional three-year rotation 
of wheat-wheat-maize was selected. In the simulation under the baseline climate condition, winter wheat was planted on September 23 and harvested on June 27 of the following year; and maize was planted on April 15 and harvested on September 22. However, under the changed climates, wheat was planted 3 days later and harvested 3 days earlier; and maize was planted 3 days earlier and harvested 3 days earlier to accommodate the increased temperature. It should be noted that overall mean of measured storm duration at Changwu station was 2.88 times that of CLIGEN-generated storm durations. To adjust this bias, a factor of 2.88 was multiplied to CLIGEN-generated storm durations and relative peak intensities in both baseline and changed climates.

\section{RESULTS AND DISCUSSIONS}

\subsection{Projected climate change}

Precipitation of Wangdonggou watershed from 2010 2039 can be projected by downscaling (Table 1, Fig. 1). Projected mean annual precipitation during 2010 2039 compared with 1957 2001 would increase by $10.8,80.6$ and $101.4 \mathrm{~mm}$ (equivalent to $1.8,13.9$ and $17.5 \%$ increase) respectively, for the A2a, B2a and GGal scenario. The projected percent increases in precipitation varied with emission scenarios. In general, three emission scenarios projected more precipitation increases in the spring and summer than in the winter and fall (Fig. 1). The most change occurred in May and from July to September, during which precipitation increased for B2a and GGal. Precipitation of A2a decreased greatly in July and August while increased rapidly during September and October.

Table 1. Averaged annual climate perturbations between 1957 2001 and 2010 2039.

\begin{tabular}{llll}
\hline Emissions Scenario & P Change $(\%)$ & Tmax Shift $\left({ }^{\circ} \mathrm{C}\right)$ & Tmin Shift $\left({ }^{\circ} \mathrm{C}\right)$ \\
\hline A2a & 1.8 & 0.9 & 2.3 \\
B2a & 13.9 & 0.5 & 2.1 \\
GGa1 & 17.5 & 0.8 & 2.0 \\
\hline
\end{tabular}

Compared with 1957 2001, projected mean annual temperature during 2010 2039 would increase by $0.9,0.5$ and $0.8^{\circ} \mathrm{C}$ for maximum temperature and increase by $2.3,2.1$ and $2.0^{\circ} \mathrm{C}$ for minimum temperature for the $\mathrm{A} 2 \mathrm{a}$, $\mathrm{B} 2 \mathrm{a}$ and GGal scenario, respectively. In general, the projected temperatures increased for each scenario; however, the increase of maximum temperature was less than that of the minimum temperature, which was consistent with the results of National Assessment Report of Climate Change (Ding et al., 2007). The monthly distributions of temperature are shown in Fig. 2. 
Generally, there were two peaks of temperature increase: one in the spring and the other in the winter, which would mean warmer winter in 2010 2039.

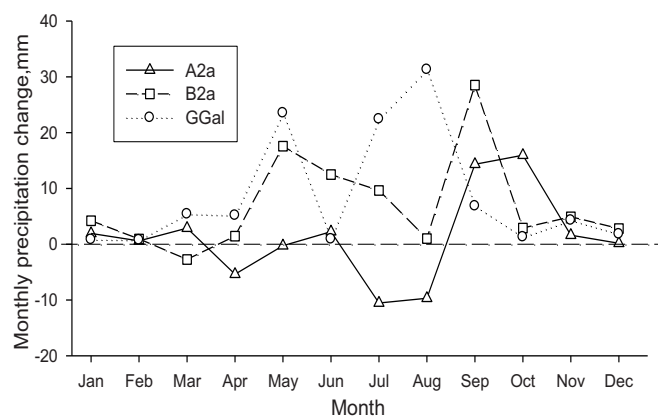

Fig. 1: Predicted change in precipitation between 1957 2001 and 2010 2039 under three emission scenarios

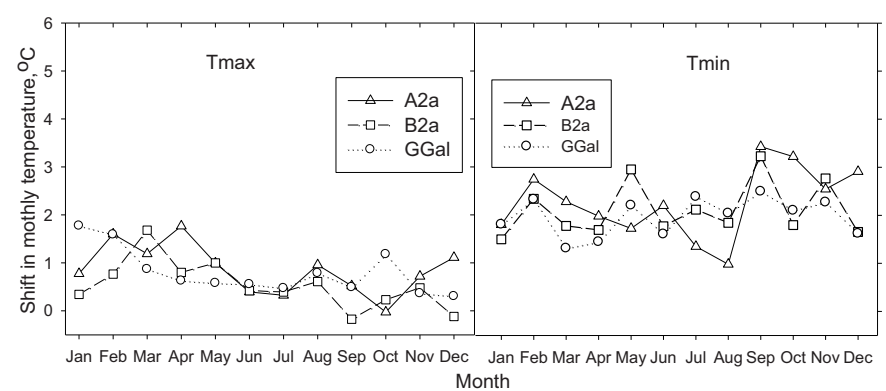

Fig. 2: Predicted change in maximum and minimum temperature between $1957 \sim 2001$ and 2010 2039 under three emission scenarios

\subsection{Monthly change of plant transpiration and soil evaporation}

Seasonal patterns of plant transpiration and soil evaporation are shown in Fig. 3. The transpiration mainly occurred from April to June, and the soil evaporation mainly occurred from July to September, which was possibly the integrated effect of precipitation change and crop growth. From April to June are the growing periods of winter wheat from disjointing stage to heading stage, during which water consumption of wheat transpiration increases rapidly and the amount of transpiration accounts for more than $80 \%$ of the total ET. The water consumption of transpiration from April to June is mainly from precipitation that varies with the three climate scenarios in 2010 2039: (i) Precipitation changes little during April, which leads to little change in plant transpiration; (ii) Precipitation decreases for A2a and increases for B2a and GGal during May, and change of transpiration exhibits the similar trend; (iii) Precipitation and transpiration increases generally for 
three scenarios. From July to September is the fallow period of Wangdonggou fields when soil evaporation reaches the peak. As the soil water supply is from precipitation, the difference of soil evaporation depends also on the precipitation change. Monthly soil evaporation from July to September has the similar trend as the precipitation (Fig. $1 \& 3$ ).

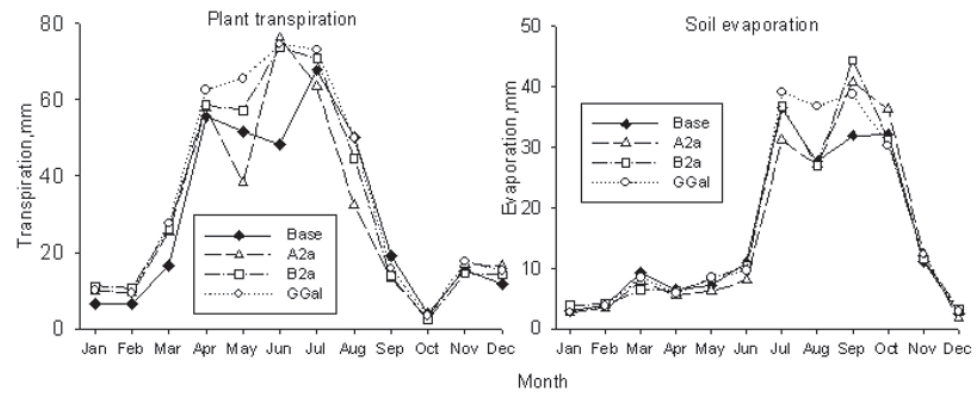

Fig. 3: The change of monthly plant transpiration and soil evaporation during 2010-2039

\subsection{Annual transpiration and soil water balance}

Predicted mean annual plant transpiration, soil evaporation, percolation, and long-term soil moisture balance in the $1.8-\mathrm{m}$ soil profile under three scenarios and two slopes are shown in Table 2. Generally, the changing trends of plant transpiration, soil evaporation and soil moisture were similar across two slopes under each scenario, which indicated the difference of these factors under two slopes is little; while the percolation at two slopes has different changing trends, with greater percolation at $5^{\circ}$ slope.

Table 2. Response of ET and soil water balance to three scenarios under conventional tillage

\begin{tabular}{|c|c|c|c|c|c|c|c|c|c|}
\hline \multirow{2}{*}{\multicolumn{2}{|c|}{$\begin{array}{l}\text { Scenario }\left(\mathrm{CO}_{2}, \mathrm{ppmv}\right) \\
\text { Slope }\end{array}$}} & \multicolumn{2}{|c|}{ Baseline(350) } & \multicolumn{2}{|c|}{$\mathrm{A} 2 \mathrm{a}(592)$} & \multicolumn{2}{|c|}{$\mathrm{B} 2 \mathrm{a}(416)$} & \multicolumn{2}{|c|}{ GGal(445) } \\
\hline & & $5^{\circ}$ & $10^{\circ}$ & $5^{\circ}$ & $10^{\circ}$ & $5^{\circ}$ & $10^{\circ}$ & $5^{\circ}$ & $10^{\circ}$ \\
\hline \multirow{2}{*}{ Transpiration } & $\operatorname{Depth}(\mathrm{mm})$ & 353 & 348 & 339 & 332 & 396 & 389 & 419 & 413 \\
\hline & Change (\%) & 0 & 0 & -4 & -5 & 12 & 12 & 19 & 19 \\
\hline \multirow{2}{*}{ Soil moisture } & $\operatorname{Depth}(\mathrm{mm})$ & 301 & 297 & 289 & 285 & 305 & 300 & 312 & 308 \\
\hline & Change (\%) & 0 & 0 & -4 & -4 & 1 & 1 & 4 & 4 \\
\hline \multirow{2}{*}{ Evaporation } & $\operatorname{Depth}(\mathrm{mm})$ & 183 & 179 & 171 & 166 & 187 & 182 & 196 & 192 \\
\hline & Change (\%) & 0 & 0 & -7 & -7 & 2 & 2 & 7 & 7 \\
\hline \multirow{2}{*}{ Percolation } & $\operatorname{Depth}(\mathrm{mm})$ & 0.58 & 0.58 & 0.87 & 0.76 & 0.58 & 0.58 & 0.83 & 0.71 \\
\hline & Change (\%) & 0 & 0 & 50 & 32 & 0 & 0 & 43 & 23 \\
\hline \multirow{2}{*}{ Wheat } & Yield $\left(\mathrm{t} \cdot \mathrm{ha}^{-1}\right)$ & 2.9 & 2.8 & 2.9 & 2.8 & 3.5 & 3.4 & 4.1 & 3.9 \\
\hline & Change(\%) & 0 & 0 & -1 & -1 & 23 & 22 & 41 & 41 \\
\hline \multirow{2}{*}{ Maize } & Yield $\left(\mathrm{t} \cdot \mathrm{ha}^{-1}\right)$ & 7 & 6.8 & 8 & 7.8 & 8.6 & 8.3 & 9.6 & 9.5 \\
\hline & Change(\%) & 0 & 0 & 15 & 14 & 23 & 22 & 38 & 38 \\
\hline
\end{tabular}

Compared with the baseline conditions, plant transpiration changed from 5 to $19 \%$ across all emissions scenarios and slopes. The percent increases averaged across all slopes were $-4.5 \%$ for A2a, $12 \%$ for B2a, and $19 \%$ for GGa1. The change of plant transpiration is the integrated effect of precipitation change and crop growth, for example, A2a predicted the least 
precipitation and crop yields, which led to the decrease of plant transpiration. The GGal scenario predicted the most precipitation increase and crop yields, which resulted in the most transpiration. Simulated soil moisture changed from -4 to $4 \%$, compared with the baseline condition, A2a decreased while B2a and GGal increased, and GGal has the most increase. Soil evaporation has the similar trend as soil moisture, changed from -7 to $7 \%$, simply because soil evaporation was mainly limited by soil water supply rather than by evaporative demand in the study region. Compared with the baseline condition, the deep percolation loss of A2a and GGal increased greatly while the B2a changed little.

\section{CONCLUSION}

With the new statistical approach, GCM grid outputs of 2010 2039 were downscaled to Wangdonggou watershed, three scenarios of A2a, B2a and GGal were developed to drive WEPP model to simulate the potential change of soil water balance under $5^{\circ}$ and $10^{\circ}$ slopes. The Hadley Centre model (HadCM3) predicted a 1.8 to $17.5 \%$ increase in annual precipitation, $0.5{ }^{\circ} \mathrm{C}$ to $0.9{ }^{\circ} \mathrm{C}$ rise in maximum temperature, and $2.0{ }^{\circ} \mathrm{C}$ to $2.3{ }^{\circ} \mathrm{C}$ rise in minimum temperature for the region, the increase of minimum temperature were more than maximum temperature, and increase of temperature mainly happened in spring and winter.

Compared with the baseline condition, the change trends of soil water balance under two slopes are similar. Change of plant transpiration and soil evaporation mainly occurred from April to June and from July to September, respectively. Compared with the baseline condition, predicted percent change under climate change, ranged from -5 to $19 \%$ for plant transpiration, -4 to $4 \%$ for soil moisture, -7 to $7 \%$ for soil evaporation, A2a decreased while B2a and GGal increased for these factors. Compared with the baseline condition, deep percolation loss of A2a increased the most, GGal intermediate and $\mathrm{B} 2 \mathrm{a}$ changed little. The above changes are mainly caused by the precipitation change and crop growth. For example, the transpiration mainly occurs from April to June when the water supply is mostly from precipitation. The transpiration changed differently according to the precipitation change. The least increase of precipitation and yields for A2a led to the decrease of transpiration, while the most increase of precipitation and yields for GGal caused the most increase of transpiration. The above results suggest that climate change would influence soil water balance significantly and some countermeasures must be taken to mitigate the adverse effect of climate change. 


\section{ACKNOWLEDGEMENTS}

This study was funded by National Natural Science Foundation of China (No. 40640420061) and the Outstanding Overseas Chinese Scholars Fund of Chinese Academy of Sciences (No. 2005-2-3).

\section{REFERENCES}

Chen, D., 2000. A monthly circulation climatology for Sweden and its application to a winter temperature case study. International Journal of Climatology, 20: 1067-1076.

Ding, Y. et al., 2007. China's National Assessment Report on Climate Change (I): Climate change in China and the Future Trend. Advances in Climate Change Research, 2(1): 3-8.

Hansen, J.W., Indeje, M., 2004. Linking dynamic seasonal climate forecasts with crop simulation for maize yield prediction in semi-arid Kenya. Agric. For. Meteo, 125: 143-157.

Huszar, T., Mika, J., Loczy, D., Molnar, K. and Kertesz, A., 1999. Climate change and soil moisture: A case study. Phys. Chem. Earth, 24(10): 905-912.

Mehrotra, R., 1999. Sensitivity of runoff, soil moisture and reservoir design to climate change in central Indian River basins. Climatic Change, 42(4): 725-757.

Naden, P.S. and Watts, C.D., 2001. Estimating climate-induced change in soil moisture at the landscape scale: An application to five areas of ecological interest in the U.K. Climatic Change, 49(4): 411-440.

Pan, Z., Arrit, R.W., Gutowski W, Jr. and Takle, E.S., 2001. Soil moisture in a regional climate model: Simulation and projection. Geophys. Res. Lett., 28(15): 2947-2950.

Ramos, M.C. and Mulligan, M., 2005. Spatial modelling of the impact of climate variability on the annual soil moisture regime in a mechanized Mediterranean vineyard. J Hydrol, 306(1-4): 287-301.

Solman, S. and Nunez, M., 1999. Local estimates of global climate change: a statistical downscaling approach. Int. J. Climatol, 19: 835-861.

von Storch, H., 1995. Inconsistencies at the interface of climate impacts studies and global climate research. Meteorologie Zeitschrift, NF4: 72-80.

Wilby, R.L. et al., 1998. Statistical downscaling of general circulation model output: A comparison of methods. Water Resources Research, 34: 2995-3008.

Zhang, X.C., 2005. Spatial downscaling of global climate model output for site-specific assessment of crop production and soil erosion. Agr. Forest. Meteorol., 135(1-4): 215-229

Zhang, X.C. and Liu, W.Z., 2005. Simulating potential response of hydrology, soil erosion, and crop productivity to climate change in Changwu tableland region on the Loess Plateau of China. Agr. Forest. Meteorol., 131: 127-142. 